\title{
MODELAGEM TEMPORAL DINÂMICA DO USO E OCUPAÇÃO DO SOLO BASEADO EM SIG PARA A BACIA DO RIO TAPACURÁ (PE)
}

\author{
A GIS-BASED METHOD FOR TEMPORAL DYNAMIC MODELLING OF THE LAND USE AND \\ LAND COVER IN THE TAPACURÁ RIVER BASIN (PE)
}

\author{
Ana Paula Campos XAVIER ${ }^{1}$, Richarde Marques da SILVA ${ }^{2}$ \\ ${ }^{1}$ UFPB - Universidade Federal da Paraíba. Centro de Tecnonologia. Programa de Pós-Graduação em Engenharia Civil e Ambiental. \\ Email: anapcxavier@gmail.com \\ ${ }^{2}$ UFPB - Universidade Federal da Paraíba. Centro de Ciências Exatas e da Natureza. Departamento de Geociências \\ Email: richarde@geociencias.ufpb.br
}

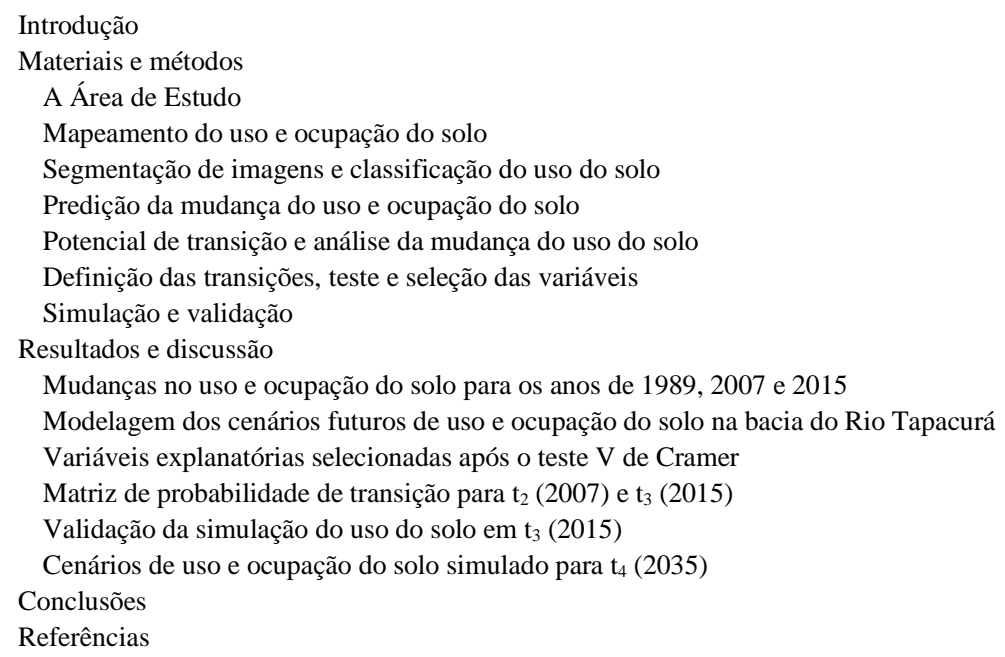

RESUMO - Este estudo teve por objetivo simular cenários de uso e ocupação do solo para $t_{4}$ (2035), tendo como base as mudanças no uso do solo ocorridas em $t_{1}$ (1989), $t_{2}$ (2007) e $t_{3}$ (2015) para a bacia do Rio Tapacurá, localizada no Estado de Pernambuco. Foi realizada a previsão do uso do solo para $t_{3}$ (2015), usando três métodos: (a) Rede Neural Multi-Layer Perceptron (RNMLP), (b) Similarity-Weighted Instance-Based Machine Learning Algorithm (SimWeight) e (c) Regressão Logística (RL) e para a metodologia que mostrou melhor desempenho, foi realizada a predição dos cenários futuros para $t_{4}$ (2035). Os cenários futuros simulados foram: (a) Cenário 1: de continuidade das transições e (b) Cenário 2: de continuidade das transições e intensificação da classe pecuária e expansão da área urbana, usando o módulo Land Change Modeler (LCM) do Idrisi TerrSet e imagens da cobertura do solo. Os resultados da previsão do uso do solo para 2015 mostraram que o melhor desempenho foi obtido usando o método RNMLP com treinamento de 84,22\% e 10.000 iterações. A simulação dos cenários futuros para $t_{4}$ mostrou intensificação das transições observadas nos três anos analisados, com previsão para expansão de cerca de 3\% da classe pecuária para os dois cenários simulados.

Palavas-chave: Modelagem, SIG, uso do solo.

ABSTRACT - The objective of this study was to simulate scenarios of uso and occupation of the soil in the Tapacurá River Basin, located in Pernambuco state, based on changes in land use in $t_{1}(1989)$ and $t_{2}(2007)$ in the basin. Land use prediction was performed for $t_{3}$ (2015), using three methods: (a) Multi-Layer Perceptron Neural Network (RNMLP), (b) Similarity- Weighted Instance- Based Machine Learning Algorithm (SimWeight), and (c) Logistic Regression (LR) and for the methodology that showed better performance, the prediction of the future scenarios was executed for $t_{4}$ (2035). The simulated future scenarios were: (a) Scenario 1 : continuity of transitions and (b) Scenario 2: continuity of transitions and intensification of the livestock class and expansion of the urban area, obtained using the module Land Change Modeler (LCM) of the Idrisi TerrSet and images of the ground cover. The results of the soil use forecast for the year of 2015 showed better performance using RNMLP with training of $84.22 \%$ and 10.000 iterations. The simulation of the future scenarios for $t_{4}$ showed intensification of the transitions observed in the three years analyzed, with an expected expansion of about $3 \%$ of the livestock class for the two simulated scenarios.

Keywords: Modelling, GIS, soil use.

\section{INTRODUÇÃO}

Uma das consequências mais notáveis do desenvolvimento das atividades humanas é a mudança no uso e ocupação do solo. O crescimento urbano e o estabelecimento de áreas de cultivo em áreas naturais são exemplos das principais mudanças no uso e ocupação do solo observado nas últimas décadas (Xiong, 2014). De acordo com Foley et al. (2005), os impactos causados pelas alterações no uso do solo caracterizam-se como uma das principais preocupações para o planejamento ambiental, uma vez que podem afetar significativamente o meio natural, não somente em escala local, mas como também nas escalas regional e global. Assim, estudar as tendências futuras da dinâmica temporal do uso do solo é de suma 
importância para o planejamento geoambiental. Principalmente, em regiões afetadas pelas constantes alterações no uso e ocupação do solo para expansão agropecuária, como é o caso da bacia do Rio Tapacurá, no Estado de Pernambuco (Santos, 2015). Essa bacia hidrográfica é uma das responsáveis pelo abastecimento de água para consumo humano e industrial de grande parte da Região Metropolitana do Recife (RMR), entretanto vem sofrendo forte pressão antrópica comprometendo a qualidade e a disponibilidade hídrica para a RMR, por causa, sobretudo da poluição dos principais rios dessa bacia, como constatados nos estudos de Silva (2010) e Santos (2015).

Assim, aliada a técnicas de Sistemas de Informações Geográficas e Sensoriamento Remoto, a modelagem dinâmica do uso do solo vem sendo bastante utilizada, pois possibilita a representação das mudanças no uso do solo de uma região em resposta a um conjunto de circunstâncias impostas ou previstas, auxiliando no planejamento territorial e dos recursos naturais (Dias e Walde, 2013).

O monitoramento das mudanças ocorridas e a predição da cobertura do solo baseada na dinâmica do uso e ocupação do solo de uma região podem ser realizados por modelos e algoritmos computacionais de detecção de mudança (Land Use and Land Cover Change LUCC). Esses modelos consideram processos sociais, ambientais, institucionais e econômicos, compreendendo uma grande quantidade de variáveis em diferentes abordagens metodológicas, possibilitando o estabelecimento de medidas para o planejamento do uso do solo (Eastman, 2011; Soares Filho et al., 2013; Mas et al., 2014). De acordo com Luiz (2014), os modelos LUCC permitem a predição de cenários a partir do entendimento de como alguns eventos podem influenciar nas mudanças no uso do solo.

Dentre os modelos LUCC pode-se destacar o Land Change Modeler (LCM), como um dos mais utilizados mundialmente em estudos relacionados à dinâmica do uso e ocupação do solo e também como subsídio a diversas pesquisas na área ambiental. Como exemplo de aplicações pode-se citar os estudos de Mishra et al. (2014) na Índia, Cheng e Ding (2016) no Estados Unidos, Khawaldah (2016) na Jordânia. No Brasil, destacam-se os estudos realizados na Amazônia (Deus, 2013), em São Paulo (Zanata, 2014; Piroli, 2014) e em Minas Gerais (Luiz, 2014).

Nessa perspectiva, este estudo busca simular cenários futuros de uso e ocupação do solo para $t_{4}$ (2035) na bacia do Rio Tapacurá, através do teste de três metodologias: (a) Rede Neural MultiLayer Perceptron (RNMLP), (b) Algo-ritmo de Aprendizagem baseado em Instâncias Ponderadas por Similaridade (Similarity-Weighted InstanceBased Machine Learning AlgorithmSimWeight), e (c) Regressão Logísti-ca (RL), tendo como base as alterações no uso do solo ocorridas em t $t_{1}$ (1989) e $t_{2}$ (2007) na bacia.

\section{MATERIAIS E MÉTODOS}

\section{A área de estudo}

A bacia do Rio Tapacurá é uma sub-bacia do Rio Capibaribe, e possui uma área de drenagem de aproximadamente $470 \mathrm{~km}^{2}$. Essa bacia está localizada na zona de transição entre a Zona da Mata e o Agreste, no Estado de Pernambuco, mais precisamente entre as latitudes $7^{\circ} 58^{\prime} 00^{\prime \prime} \mathrm{S}$ e $8^{\circ} 13^{\prime} 00^{\prime \prime} \mathrm{S}$ e as longitudes $35^{\circ} 05^{\prime} 00^{\prime \prime} \mathrm{O}$ e $35^{\circ} 30^{\prime} 00^{\prime \prime} \mathrm{O}$ (Braga, 2001). A bacia do Rio Tapacurá abrange os municípios de Vitória de Santo Antão, Pombos, São Lourenço da Mata, Gravatá, Moreno e Chã Grande (Figura 1).

Os municípios de Vitória de Santo Antão e Pombos são os mais importantes para a bacia do Rio Tapacurá, por ocuparem um maior percentual de área da bacia, respectivamente com $38,6 \%$ e 31,2\%. O Rio Tapacurá possui comprimento de
72,6 km, considerando os meandros do seu percurso desde a nascente, no município de Gravatá, até a desembocadura no Rio Capibaribe, no município de São Lourenço da Mata, do qual é o principal afluente (Dutra, 2005).

De acordo com a classificação climática de Köeppen, a região da bacia Tapacurá é do tipo As', com clima quente e úmido do tipo tropical. A bacia se estende de Oeste, no começo da região Agreste, com precipitação anual de 800 mm, até a zona da mata, a leste, com valores de precipitação anual até $1.650 \mathrm{~mm}$ (Silva et al., 2012). O período chuvoso da bacia ocorre entre os meses de março a julho, com temperatura média mensal oscilando entre 23 e $27{ }^{\circ} \mathrm{C}$, enquanto a umidade relativa do ar, durante os meses de maio a agosto é superior a $75 \%$ (Duarte, 2009; Oliveira et al., 2012). 


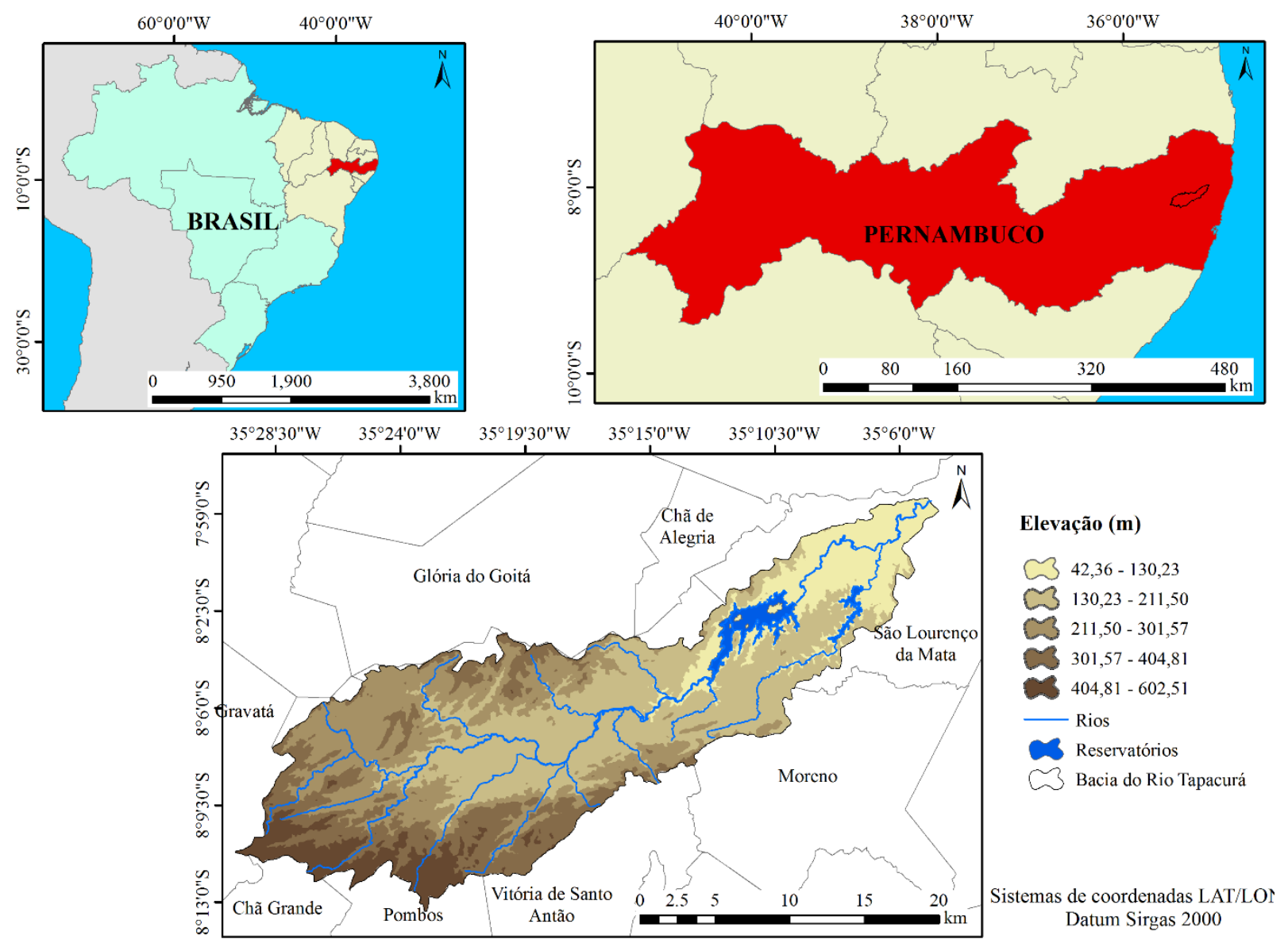

Figura 1 - Localização geográfica da bacia do Rio Tapacurá, Estado de Pernambuco.

Os solos predominantes na bacia do Rio Tapacurá, segundo a nova classificação de solos proposta pela Embrapa (2013), são Gleissolos, Neossolos Litólicos, Planossolos, Neossolos Flúvicos, Luvissolos Crômicos, Neossolos Regolíticos, Latossolos e Argissolos. Quanto ao grupo hidrológico, na bacia do Rio Tapacurá, encontram-se disseminados os solos pertencentes ao grupo hidrológico C, abrangendo $73,76 \%$ da área da bacia.

O grupo C compreende os solos contendo baixa taxa de infiltração quando completamente molhados, principalmente com camadas que dificultam o movimento da água através das camadas superiores para as inferiores, ou com textura moderadamente fina e baixa taxa de infiltração, com taxa mínima de infiltração de 1,27-3,81 mm/h (Castro, 2013).

O relevo da bacia é constituído, em sua maior parte, por colinas e cristas. As colinas predominam na parte oriental da bacia, próximo à confluência do Rio Tapacurá com o Rio Capibaribe e chegam até o leste do município de Pombos. Na parte ocidental da bacia a partir do distanciamento da calha do Rio Tapacurá, tanto para o norte como para o sul a altitude dos topos eleva-se gradualmente, enquanto que as colinas vão cedendo lugar aos relevos mais contínuos e orientados, constituindo as cristas (Braga, 2001).

\section{Mapeamento do uso e ocupação do solo}

Para o mapeamento do uso e ocupação do solo na bacia em $t_{1}$ (1989), $t_{2}$ (2007) e $t_{3}$ (2015), foram utilizadas duas imagens, com resolução espacial de $30 \mathrm{~m}$, do sensor TM a bordo do Landsat- 5, na órbita 214 e ponto 66, de julho de 1989 e agosto de 2007 obtidas através do catálogo de imagens do Instituto Nacional de Pesquisas Espaciais (INPE). Para o ano de 2015, devido à indisponibilidade de imagens Landsat sem presença de nuvens no limite da bacia, utilizou-se uma imagem de alta resolução espacial, do sensor Quickbird, referente ao ano de 2015, com resolução espacial de $1 \mathrm{~m}$, obtida através do software Google Earth (Google, 2015).

A escolha das imagens de satélite foi determinada pela distribuição das nuvens em cada imagem, pois a significativa presença de nuvens dificulta a identificação dos elementos nas imagens. Dessa forma, foram escolhidas as imagens sem presença ou com poucas 
nuvens, que não prejudicasse a identificação dos elementos, para o período analisado.

Para a melhor identificação das classes de uso e ocupação do solo nas imagens do Landsat, a composição colorida utilizada foi 5(R) 4(G) 3(B). Em seguida, as imagens foram georreferenciadas em ambiente SIG, utilizando o software ArcGis versão $10.1^{\circledR}$, usando 10 pontos de controle distribuídos espacialmente na bacia, obtidos na carta topográfica de Vitória de Santo Antão (SC.25-V-A-II), na escala 1:100.000. As imagens georreferenciadas foram utilizadas nos processos de segmentação e classificação de imagens. A figura 2 mostra os procedimentos metodológicos gerais empregados para o desenvolvimento deste estudo.

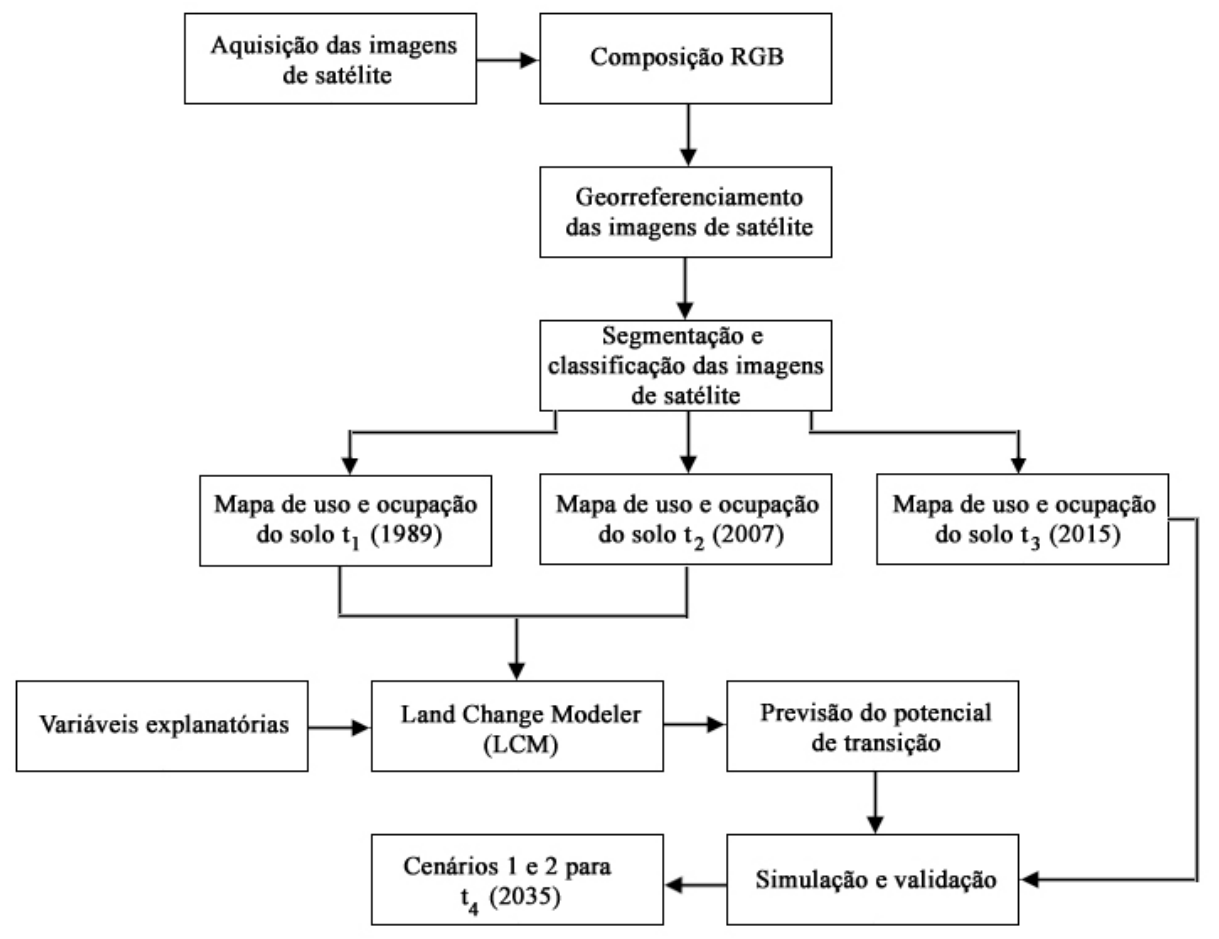

Figura 2 - Procedimentos metodológicos utilizados na predição do uso do solo.

\section{Segmentação de imagens e classificação do} uso do solo

Os processos de segmentação e classificação de imagens foram executados através do software SPRING versão 5.3. A segmentação da imagem foi realizada pelo algoritmo segmentação por crescimento de regiões. Neste estudo foram testados os valores de similaridade e área de: (a) 15 e 20 pixels; (b) 20 e 30 pixels; (c) 30 e 30 pixels; (d) 10 e 15 pixels e (e) 13 e 20 pixels. Com base no critério visual dos polígonos gerados na fase da segmentação da imagem, a combinação de similaridade e área que melhor representou as regiões, sobretudo de água (reservatórios) e urbana, foi a similaridade de 15 e 20, e 13 e 20 pixels para os anos de 1989 e 2007, respectivamente, e de 30 e 30 pixels para o ano de 2015. Em seguida, iniciou-se a classificação não supervisionada da imagem utilizando o classificador ISOSEG com um limiar de aceitação de 99\%. A classificação não supervisionada resultou em sete classes temáticas de uso e ocupação do solo, para o período analisado, que foram então definidas de acordo os tipos de uso do solo existentes na bacia: (a) vegetação arbustiva; (b) água; (c) área urbana; (d) cana-de-açúcar; (e) agricultura; (f) pecuária e (g) mata.

A classe vegetação arbustiva, neste estudo, corresponde à vegetação com porte de até $1,5 \mathrm{~m}$, basicamente composta por vegetação do tipo capoeira, e herbácea. As áreas classificadas como agricultura, referem-se às atividades com cultivo de milho, feijão, macaxeira e batata-doce; algumas frutas, como manga, jaca, goiaba, mamão, caju, jambo, abacate e pinha, uma ou mais culturas comerciais, como abacaxi, limão, laranja, banana, mandioca, maracujá, inhame e graviola; e algumas hortaliças, como alface, coentro, cebolinha, pimentão, quiabo, maxixe, berinjela, pepino, chuchu, hortelã, manjericão e arruda. A classe denominada área urbana, identificada na classificação das imagens, corresponde ao aglomerado urbano das cidades 
de Vitória de Santo Antão e Pombos, além da BR-232 que ligam essas duas cidades.

\section{Predição da mudança do uso e ocupação do solo}

Para a simulação dos cenários de uso e ocupação do solo para o ano de 2035, na bacia do Rio Tapacurá, foi utilizado o LCM integrado ao IDRISI TerrSet. Neste trabalho, para a predição da mudança do uso e ocupação do solo para o ano de 2035 foram utilizadas as seguintes opções: (a) Análise de Mudanças, (b) Potenciais de Transição e (c) Predição de mudança, que segundo Eastman (2016) correspondem: (1) Análise de Mudanças: Analisa a mudança da cobertura do solo em $t_{1} \mathrm{e}$ $t_{2}$; (2) Potenciais de Transição: Modelagem dos potenciais de transições da cobertura do solo; e (3) Previsão de mudança: Predição da mudança da cobertura do solo.

A figura 3 mostra a metodologia utilizada na predição do uso e ocupação do solo para $t_{4}$ (2035) para a bacia do Rio Tapacurá usando o LCM. A metodologia utilizada, na predição do uso do solo, foi composta basicamente pelas etapas de previsão do potencial de transição e simulação e validação, em que os principais dados de entrada foram: (a) mapa de uso e ocupação do solo em $t_{1}$ (1989), (b) uso do solo em $t_{2}$ (2007), (c) variáveis explanatórias e (d) mapa da cobertura do solo em $t_{3}$ (2015), sendo este último mapa usado na etapa de validação da simulação para $t_{3}$ (2015).

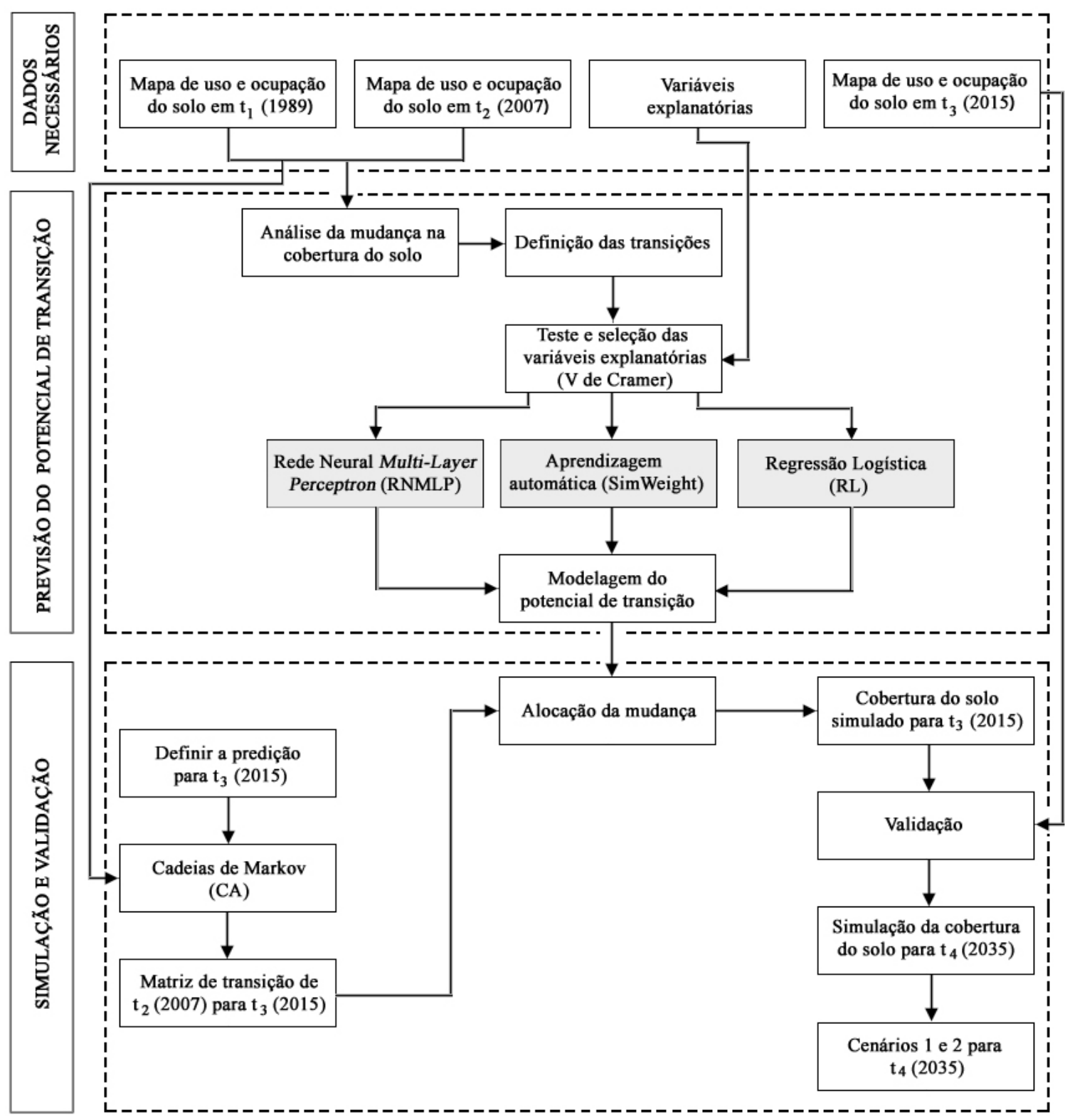

Figura 3 - Metodologia para predição do uso e ocupação do solo para t 4 (2035) para a bacia do Rio Tapacurá. Fonte: Adaptado de Luiz (2014). 


\section{Potencial de transição e análise da mudança do uso do solo}

A etapa de previsão do potencial de transição foi composta por: (a) análise da mudança na cobertura do solo, (b) definição das transições, e (c) teste e seleção das variáveis explanatórias. Em seguida foi realizado o teste $\mathrm{V}$ de Cramer, no qual foram testadas três metodologias para a modelagem do potencial de transição para $t_{3}$ (2015): (a) Rede Neural Multi-Layer Perceptron (RNMLP), (b) Algoritmo de Aprendizagem baseado em Instâncias Ponderadas por Similaridade (Similarity -Weighted Instance-Based Machine Learning Algorithm - SimWeight), e (c) Regressão Logística (RL).

$\mathrm{O}$ teste $\mathrm{V}$ de Cramer é uma análise estatística não paramétrica, ou seja, é aplicável independente da distribuição das variáveis. Essa análise é utilizada para medir a força de associação entre variáveis (Liebertrau, 1983; Sampaio, 2014; Luiz, 2014). Por meio desse teste, foi possível verificar a associação das variáveis explanatórias com as transições definidas. Esse teste é obtido pela Eq. 1 (Liebertrau, 1983):

$$
V=\sqrt{\frac{\chi^{2}}{n(q-1)}}
$$

em que: $\chi^{2}=$ coeficiente Qui-quadrado (Eq. 2):

$$
\chi^{2}=\frac{(O-E)^{2}}{2}
$$

sendo: $\mathrm{V}=$ índice $\mathrm{V}$ de Cramer; $n=$ tamanho da amostra; $q=$ menor valor das linhas e colunas da imagem da cobertura do solo; $O=$ frequência observada para uma categoria e $E=$ frequência esperada na categoria correspondente. $\mathrm{O} V$ de Cramer varia entre 0 e 1 e quanto mais próximo de 1 , maior é a associação entre a variável explanatória e a transição definida. Se o valor do V de Cramer das variáveis for maior que 0,15 , verifica-se que a variável é significativa para a modelagem e deve ser adicionada na etapa de previsão do potencial de transição (Sampaio, 2014; Hamdy et al., 2017 e Amorim, 2015).
A análise das mudanças na cobertura do solo para 2015 foi realizada com base nos mapas de uso e ocupação do solo de $t_{1}$ (1989) e $t_{2}$ (2007), servindo como subsídio para a definição das transições, isto é, para identificação das mudanças de uma determinada classe para outra.

\section{Definição das transições, teste e seleção das variáveis explanatórias}

As transições foram definidas com base nas mudanças observadas no uso e ocupação do solo em $t_{1}$ (1989), $t_{2}$ (2007) e $t_{3}$ (2015). Dessa maneira, para a modelagem do potencial de transição, foram escolhidas as seguintes transi-ções: (a) Vegetação arbustiva para pecuária; (b) Vegetação arbustiva para agricultura; (c) Vegetação arbustiva para área urbana e (d) Vegetação arbustiva para canade-açúcar. Essas transições foram escolhidas, em razão da diminuição das áreas ocupadas pela classe de vegetação arbustiva para expansão de áreas destinadas à pecuária, agricultura, área urbana e cana-de-açúcar, que foram identificadas ao longo dos anos analisados.

A seleção das variáveis explanatórias foi baseada no teste $\mathrm{V}$ de Cramer, disponibilizado pelo LCM, para avaliar as variáveis que mais influenciaram no processo de mudança no uso e ocupação do solo na bacia. Neste estudo, apenas as variáveis explanatórias com valores de $\mathrm{V}$ de Cramer superiores a 0,15 foram utilizadas na modelagem da predição do uso e ocupação do solo na bacia do Rio Tapacurá.

As variáveis explanatórias correspondem aos fatores que podem influenciar na mudança do uso do solo na bacia, por exemplo: altitude, distância de cursos d'água, distância de rodovias, distância de núcleos urbanos, tipos de solo, declividade, dentre outras. Segundo Sangermano et al. (2012), as principais variáveis que influenciam na tendência das mudanças são (a) a distância de rodovias, (b) de cursos de água, (c) de áreas urbanas, (d) declives, e (e) Modelo Digital do Terreno (MDT). Baseada nas mudanças do uso e ocupação do solo na bacia e no conhecimento da área de estudo, foram testadas as seguintes variáveis explanatórias: (a) distância de rodovias; (b) distância de 
cursos d’água e reservatórios; (c) distância de áreas urbanas; (d) declividade; e (e) altitude. A variável distância de rodovias foi obtida mediante o shapefile do sistema viário do Estado de Pernambuco, disponível no banco de dados da Fundação do Patrimônio Histórico e Artístico de Pernambuco (FUNDARPE, 2016), disponível em: http://www.mapacultural.pe. gov.br/inicial /shapefile.htm.

Em seguida, foi calculada a distância da rede viária, através do comando DISTANCE do IDRISI TerrSet, dando origem a uma nova imagem, em que o valor armazenado em cada célula é a menor distância entre ela e a feição mais próxima. O mesmo procedimento foi realizado para as variáveis de distância de cursos d'água e reservatórios e distância de áreas urbanas. Para a obtenção das variáveis de declividade e altitude, foi utilizado o MDT, com resolução espacial de $30 \mathrm{~m}$, adquirido junto ao Instituto Nacional de Pesquisas Espaciais (Valeriano, 2005; Valeriano et al., 2009), disponível em http://www.dsr.inpe.br/ topodata.

\section{Simulação e validação}

A partir da modelagem do potencial de transição, foi especificado o tempo t3, ou seja, o ano com o uso do solo previsto. Para tanto, a probabilidade de mudança foi modelada através da Cadeia de Markov (CM). A CM descreve a probabilidade de mudança da cobertura do solo a partir de um período para outro, através do desenvolvimento de uma matriz de probabilidade de transição de t2 para $\mathrm{t} 3$. As probabilidades podem ser precisas por categoria, mas não há conhecimento da distribuição espacial das ocorrências dentro de

cada classe de cobertura do solo (Eastman, 2003).

Após a matriz de transição utilizando a CM, foi obtido o mapa de cobertura do solo simulado para $t_{3}$ (2015). Em seguida, foi realizada a validação de $t_{3}$ para cada mapa simulado com RNMLP, SimWeight e RL. Para essa validação foram necessários os mapas de uso e ocupação do solo em: (a) t $t_{2}$ (2007); (b) mapa simulado de $t_{3}$ (2015), e (c) mapa de uso e ocupação do solo classificado para $t_{3}$ (2015). Essa validação resultou na espacialização: (a) das áreas com acerto da previsão (alterou), (b) das áreas com erro da previsão, e (c) das áreas com acerto da previsão (não alterou), ou seja, das áreas que não apresentaram mudanças no uso do solo.

A simulação do mapa de uso e cobertura do solo para $t_{4}$ (2035) foi realizada após a previsão do potencial de transição e escolha do método da modelagem do potencial de transição, que apresentou o melhor desempenho na predição para $t_{3}$ (2015). Dessa forma, foram simulados dois cenários para 2035:

(a) Cenário 1: Cenário simulado baseado nas tendências identificadas na bacia em $t_{1}$ (1989), $t_{2}$ (2007) e $t_{3}$ (2015), ou seja, na mudança da classe de vegetação arbustiva por áreas de pecuária, agricultura, área urbana e cana-de-açúcar, e

(b) Cenário 2: Esse cenário simulado também foi determinado baseado nas tendências identificadas na bacia em $t_{1}$ (1989), $t_{2}$ (2007) e $t_{3}$ (2015), entretanto, para esse cenário foi considerada a intensificação da classe pecuária e expansão da classe de área urbana.

\section{RESULTADOS E DISCUSSÃO}

A figura 4a mostra a espacialização das classes temáticas de uso e ocupação do solo, que foram identificadas a partir da classificação não supervisionada da imagem de satélite para o ano de 1989, na bacia do Rio Tapacurá. Nesse ano, a maior parte da bacia era ocupada por vegetação arbustiva $(83,02 \%)$, por pecuária (7,78\%) e agricultura (3,43\%). A classe mata ocupava 13,02 $\mathrm{km}^{2}$, ocorrendo principalmente em áreas próximas ao reservatório Tapacurá, e em alguns pontos isolados nas porções nordeste e sudoeste da bacia.
As classes cana-de-açúcar e área urbana foram aquelas que ocupavam a menor área, com apenas 0,25\% e 0,95\% da área da bacia, respectivamente. Foi observado ainda que na classificação de 1989, a bacia possuía apenas um reservatório de abastecimento d’água, mais especificamente, o reservatório Tapacurá, localizado no município de São Lourenço da Mata e por pequenos corpos d'água identificados na imagem de satélite. A classe água em 1989 correspondia a 1,79\%.

A figura $4 \mathrm{~b}$ mostra o mapa de uso e 
ocupação do solo da bacia do Rio Tapacurá para o ano de 2007. Observou-se que as classes de vegetação arbustiva, agricultura e pecuária continuaram sendo aqueles usos com maiores percentuais na bacia, com 18,30, 45,41 e 16,99\%, respectivamente. Todavia, foi veri-ficado que a vegetação arbustiva apresentou redução para os anos de 1989 e
2007 de 390,19 km² para 86,01 km². Esse resultado deveu-se ao fato da expansão e, sobretudo da intensificação da monocultura de cana-de-açúcar, juntamente com o crescimento das áreas de cultivo de milho, feijão, abacaxi, dentre outros, que correspondem à classe denominada de agricultura.
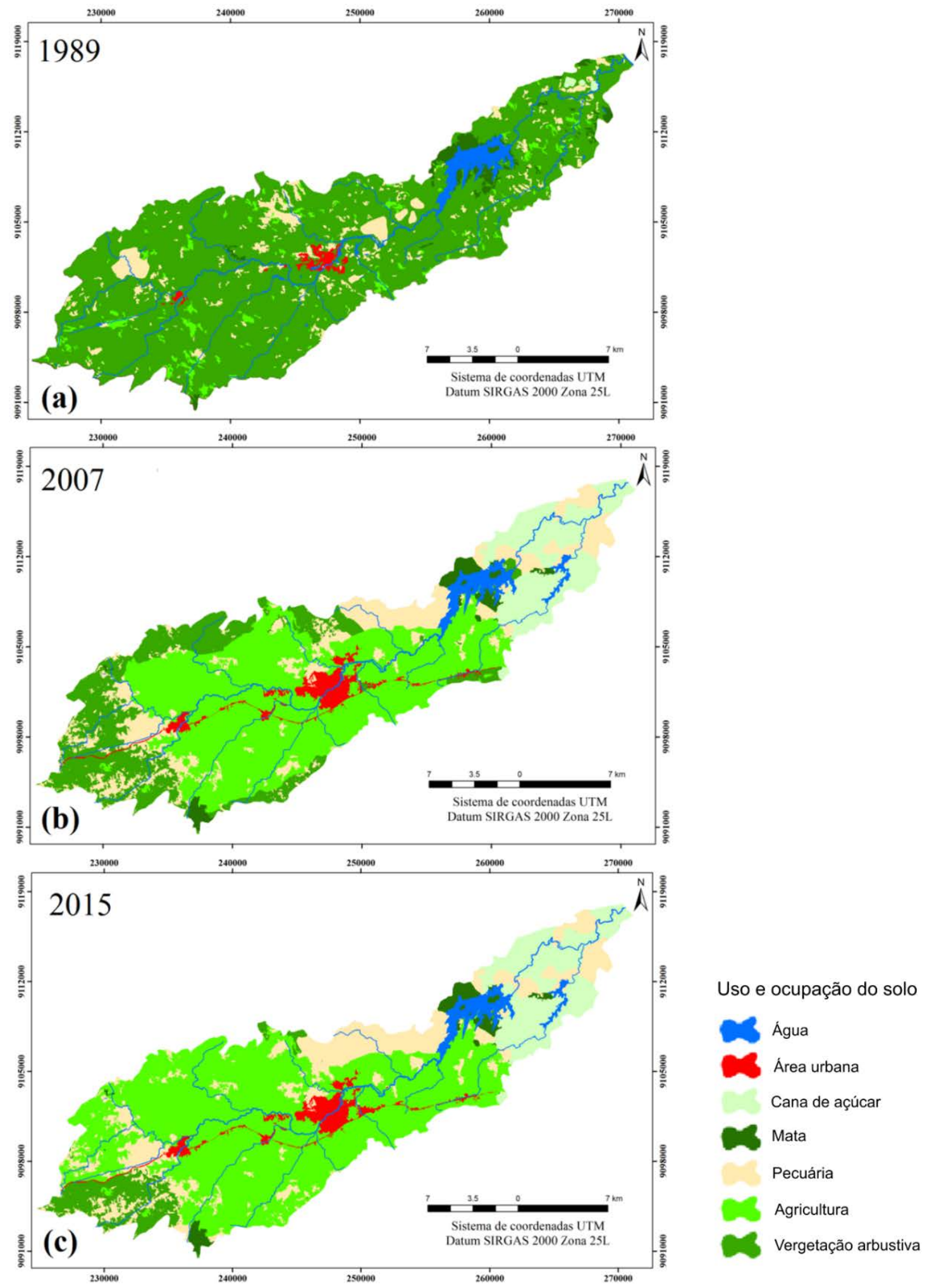

Figura 4 - Mapas de uso e ocupação do solo da bacia do Rio Tapacurá em: (a) $t_{1}$ (1989), (b) $t_{2}$ (2007), e (c) $t_{3}$ (2015). 
A classe água apresentou um acréscimo de 2,19 km², comparando-se com o ano de 2007. Esse resultado deveu-se a expansão do sistema de abastecimento de água da RMR, com a construção do reservatório Várzea do Una. Como esperado, observou-se ainda que as maiores alterações ocorridas para os anos de 1989 e 2007 foram em locais com baixas altitudes, sendo essas áreas mais susceptíveis as ações antrópicas, principalmente para atividades agropecuárias. Contrariamente, nas áreas com maiores altitudes, a classe vegetação arbustiva continuou prevalecendo, principalmente na porção sudoeste da bacia. No que tange a evolução da classe área urbana, pode-se notar que esta aumentou de $0,95 \%$ para $3,32 \%$, devido principalmente ao acréscimo do aglomerado urbano dos municípios de Vitória de Santo Antão e Pombos.

A figura 4c mostra o mapa temático do uso e ocupação da obtido para $t_{3}$ (2015). Para esse ano, a classe vegetação arbustiva apresentou uma área total de $27,06 \mathrm{~km}^{2}$, isto é, uma redução de aproximadamente $77 \%$, comparando-se ao ano de 1989. Essa classe ocupava áreas somente na porção sudoeste da bacia. A classe mata apresentou uma redução de 3,17 km² para os anos de 1989 e 2015. Verificou-se em 2015 o predomínio das classes de cana-de-açúcar $\left(55,90 \mathrm{~km}^{2}\right)$, agricultura $\left(263,21 \mathrm{~km}^{2}\right)$ e pecuária $\left(87,50 \mathrm{~km}^{2}\right)$. Observouse também um aumento de $11,42 \mathrm{~km}^{2}$ da classe área urbana, quando comparado com o ano de 1989. Na porção leste e com declividades mais baixas na bacia, houve uma concentração de atividades agrícolas, especialmente com a presença da cana-de-açúcar, com 11,89\% da área total da bacia. As áreas ocupadas pela classe agricultura em 2015 apresentaram crescimento de 52,57\% em comparação com 1989. A classe água mostrou aumento de $2,18 \mathrm{~km}^{2}$ para o período entre 1989 e 2015.

O mapeamento do uso e ocupação do solo na bacia mostrou que as áreas ocupadas por vegetação arbustiva, cada vez mais foram substituídas pelas classes agricultura, cana-deaçúcar e pecuária entre os anos analisados. Comparando os anos de 1989 e 2015 foi identificado também o aumento de aproximadamente $2,5 \%$ da classe de área urbana. Na tabela 1, podem ser visualizados os resultados das áreas ocupadas de cada classe de uso e ocupação do solo para os anos de 1989, 2007 e 2015 na bacia do Rio Tapacurá.

Tabela 1 - Área de abrangência das classes de uso e ocupação do solo para os anos de 1989, 2007 e 2015 na bacia do Rio Tapacurá.

\begin{tabular}{|c|c|c|c|c|c|c|}
\hline \multirow{2}{*}{$\begin{array}{l}\text { Uso e ocupação } \\
\text { do solo }\end{array}$} & \multicolumn{2}{|l|}{1989} & \multicolumn{2}{|l|}{2007} & \multicolumn{2}{|l|}{2015} \\
\hline & Área $\left(\mathrm{km}^{2}\right)$ & $\%$ & Área $\left(\mathbf{k m}^{2}\right)$ & $\%$ & Área $\left(\mathbf{k m}^{2}\right)$ & $\%$ \\
\hline Água & 8,41 & 1,79 & 10,60 & 2,26 & 10,59 & 2,25 \\
\hline Área urbana & 4,47 & 0,95 & 15,59 & 3,32 & 15,89 & 3,38 \\
\hline Cana-de-açúcar & 1,19 & 0,25 & 54,66 & 11,63 & 55,90 & 11,89 \\
\hline Mata & 13,02 & 2,77 & 9,85 & 2,10 & 9,85 & 2,10 \\
\hline Pecuária & 36,58 & 7,78 & 79,87 & 16,99 & 87,50 & 18,62 \\
\hline Agricultura & 16,14 & 3,43 & 213,42 & 45,41 & 263,21 & 56,00 \\
\hline Vegetação arbustiva & 390,19 & 83,02 & 86,01 & 18,30 & 27,06 & 5,76 \\
\hline
\end{tabular}

Modelagem dos cenários futuros de uso e ocupação do solo na bacia do Rio Tapacurá

Com base nos mapas de uso e ocupação do solo em $t_{1}$ (1989) e $t_{2}$ (2007), utilizando o LCM: (a) o gráfico de perdas e ganhos para cada classe de cobertura do solo e (b) o mapa com as áreas de mudança e persistência, que serviram de auxílio para a definição das transições. A figura 5 apresenta as perdas e ganhos por categoria de uso e ocupação do solo em 1989 e 2007. A partir do gráfico de perdas e ganhos, foi possível identificar a diminuição ou aumento de área de cada classe de uso e ocupação do solo. Observou-se que a perda de área ocupada mais significativa ocorreu para a classe de vegetação arbustiva. Já os maiores ganhos de área ocupada foram obtidos para as classes de agricultura, pecuária e cana-deaçúcar. Como esperado, a classe de área urbana apresentou apenas ganho de área ocupada.

A figura 6 apresenta o mapa de persistência para cada classe de uso e ocupação do solo e as áreas que apresentaram mudanças de classe na bacia do Rio Tapacurá, observadas para os anos de 1989 e 2007. O mapa de mudança e persistência aponta as áreas que mudaram de uma classe para outra, e as áreas que não sofreram mudanças no uso e ocupação do solo. As áreas na 
cor laranja são os locais que mostraram mudanças no uso do solo, enquanto que as outras cores do mapa representam as classes que permaneceram inalteradas entre 1989 e 2007.

Como pode ser verificada na figura 6 , a classe vegetação arbustiva continuou ocupando a porção oeste da bacia, principalmente nas áreas com maiores declividades. Já as áreas da bacia que apresentaram mudanças no uso e ocupação do solo foram a porção central e aquelas próximas ao exutório (nas declividades mais baixas). Verificou-se que próximo ao exutório da bacia, aproximadamente $9 \%$ da área ocupada pela classe vegetação arbustiva foi substituída por cana-de-açúcar.
Observou-se também que 38\% das áreas ocupadas por vegetação arbustiva foram substituídas por agricultura em 2007, ocorrida, principalmente ao longo da porção central da bacia. Pode-se destacar que essa transição foi responsável pelas maiores mudanças no uso e ocupação do solo na bacia entre 1989 e 2007. Com relação à classe área urbana, cerca de $2 \%$ da área ocupada por vegetação arbustiva foi alterada, em razão do aumento da área urbana na porção central e oeste da bacia em 2007, devido ao crescimento urbano dos municípios de Vitória de Santo Antão e Pombos para os anos de 1989 e 2007.

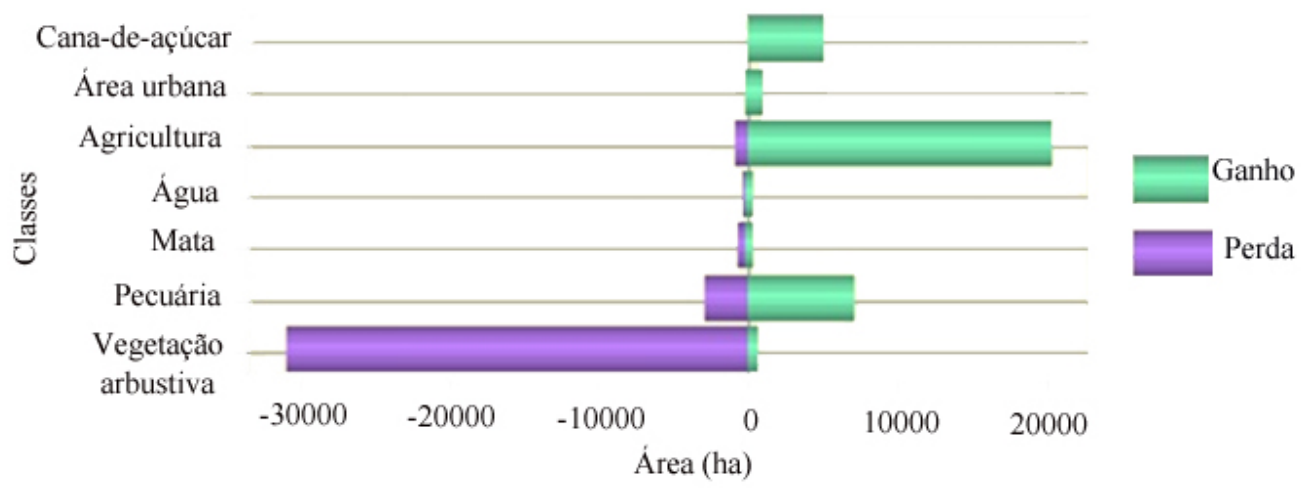

Figura 5 - Ganho e perda de áreas ocupadas por categoria de uso e ocupação do solo na bacia do Rio Tapacurá.

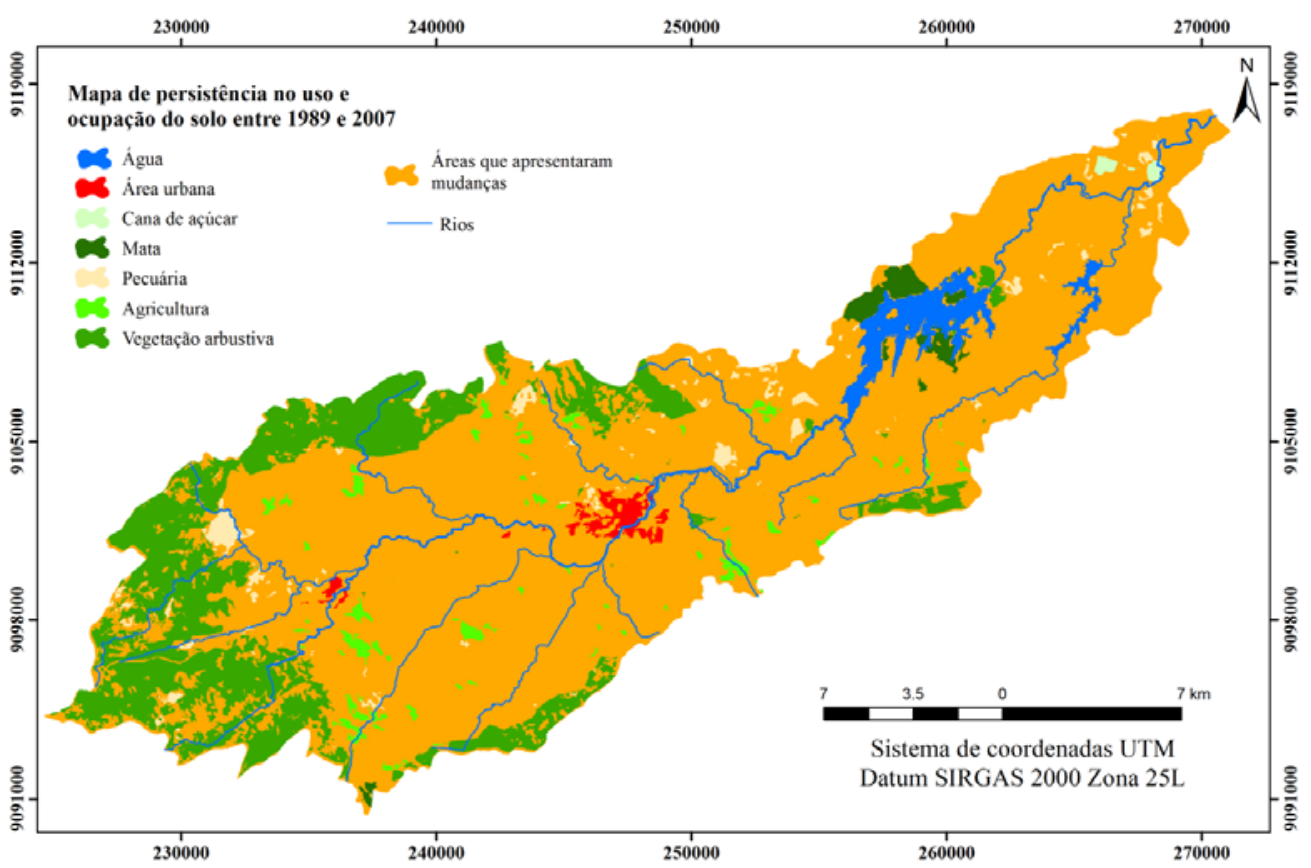

Figura 6 - Mapa de persistência e áreas de mudanças no uso e ocupação do solo para os anos de 1989 e 2007 na bacia do Rio Tapacurá

Variáveis explanatórias selecionadas após o teste V de Cramer

A tabela 2 mostra as variáveis explanatórias testadas e os resultados do teste V de Cramer.
Verificou-se que as variáveis explanatórias apresentaram valores do teste de $\mathrm{V}$ de Cramer maiores do que 0,15 , sendo as variáveis de distâncias de áreas urbanas e altitude as mais 
significativas de acordo com esse teste. Esse resultado indicou, segundo Eastman (2016), a forte relação, principalmente da elevação do terreno sobre as mudanças no uso e ocupação do solo na bacia do Rio Tapacurá, sendo as áreas com menores altitudes mais propícias as alterações por atividades de pecuária e cultivo na bacia.

A variável de distâncias de áreas urbanas apresentou o maior valor no teste $\mathrm{V}$ de Cramer $(0,4112)$, isto é, quanto mais próxima da área urbana, maior é a possibilidade de uma área vizinha ser substituída pela classe de área urbana. A variável distância de cursos d’água e reservatórios apresentou um dos menores valores para esse teste, sendo considerada não significativa para a modelagem da previsão do uso e ocupação do solo na bacia.

Após a previsão do potencial de transição com base em RNMLP, que foi simulado a partir das iterações entre as variáveis explanatórias selecionadas, o melhor resultado do treinamento foi de $84,22 \%$, com 10.000 iterações. Para Sampaio (2014) e Barreto et al. (2011), esse resultado mostra significativa relação entre as transições definidas e as variáveis explanatórias.

Tabela 2 - Resultados do teste V de Cramer para as variáveis explanatórias.

\begin{tabular}{c|c}
\hline Variável explanatória & Resultado do teste V de Cramer \\
\hline Distância de rodovias & 0,2108 \\
Distância de cursos d’água e reservatórios & 0,1195 \\
Distância de áreas urbanas & 0,4112 \\
Declividade & 0,1081 \\
Altitude & 0,3645 \\
\hline
\end{tabular}

\section{Matriz de probabilidade de transição para $t_{2}$ (2007) e $t_{3}$ (2015)}

A tabela 3 apresenta a matriz de probabilidade de transição do uso e ocupação do solo para $t_{2}$ (2007) e $t_{3}$ (2015) obtida pela CM. Na matriz de transição, as linhas correspondem às categorias de uso e ocupação do solo em $t_{2}$ (2007) e as colunas ao período $t_{3}$ (2015). Os resultados da diagonal, destacados na cor cinza, representam os percentuais de persistência, enquanto que os demais resultados correspondem aos percentuais de mudança de uma categoria de cobertura do solo para outra. A matriz de transição por CM mostrou que para um período de oito anos, as classes de área urbana, cana-de-açúcar e água apresentaram maiores probabilidades para persistência de classe, com 99,30\%, 87,39\% e 84,89\%, respectivamente. Enquanto que, a classe mata apresentou $61,08 \%$ de probabilidade para persistência e as classes vegetação arbustiva e pecuária mostraram as menores tendências para permanecerem com mesma classe de cobertura do solo $(23,94 \%$ e $26,93 \%$, respectivamente).

Tabela 3 - Matriz de probabilidade de transição das categorias de uso e ocupação do solo para $t_{2}(2007)$ e $t_{3}$ (2015) na bacia do Rio Tapacurá

\begin{tabular}{c|cccccccc}
\hline 2007 & Pegetação & Átária & Aata & Agricultura & $\begin{array}{c}\text { Área } \\
\text { urbana }\end{array}$ & $\begin{array}{c}\text { Cana-de- } \\
\text { açúcar }\end{array}$ \\
\hline $\begin{array}{c}\text { Vegetação } \\
\text { arbustiva }\end{array}$ & 0,2394 & 0,1682 & 0 & 0,0054 & 0,5075 & 0,0152 & 0,0643 \\
\hline Pecuária & 0,0356 & 0,2693 & 0 & 0 & 0,5719 & 0,0411 & 0,0821 \\
\hline Mata & 0,0029 & 0,2356 & 0,6108 & 0,1005 & 0 & 0 & 0,0501 \\
\hline Água & 0,0123 & 0,0066 & 0,0343 & 0,8489 & 0,0757 & 0,0173 & 0,0049 \\
\hline Agricultura & 0,2479 & 0,1237 & 0,0546 & 0 & 0,5242 & 0 & 0,0496 \\
\hline Área urbana & 0 & 0,0018 & 0 & 0,0001 & 0,0051 & 0,9930 & 0 \\
\hline $\begin{array}{c}\text { Cana-de- } \\
\text { açúcar }\end{array}$ & 0 & 0,1244 & 0,0015 & 0,0002 & 0 & 0 & 0,8739 \\
\hline
\end{tabular}


Foi observado a partir da matriz de transição que, apesar das mudanças na bacia do Rio Tapacurá de áreas destinadas a práticas de cultivo e pecuária, observadas em 1989 e 2007, a maioria das classes de uso e ocupação do solo apresentaram percentuais maiores que 50\% para persistência, exceto para as classes vegetação arbustiva e pecuária. Cerca de 50\% das áreas ocupadas pela classe vegetação arbustiva apresentaram tendência a serem substituídas pela classe agricultura, enquanto que 16,82\% mostraram tendência de conversão para a classe pecuária, e 6,43\% para cana-deaçúcar. Esses resultados obtidos mostraram uma significativa probabilidade para $\mathrm{t}_{3}$ (2015) das áreas ocupadas por vegetação arbustiva serem alteradas para práticas agrícolas e pecuárias, quando comparado com as outras classes de cobertura do solo.

Notou-se ainda que, a classe pecuária apresentou 57,19\% de probabilidade de ser alterada para agricultura. Esse resultado pode estar relacionado às alterações no uso e ocupação da bacia em $t_{1}$ (1989) e $t_{2}$ (2007), em que algumas áreas ocupadas por pecuária foram alteradas para agricultura (próxima à área urbana de Vitória de Santo Antão), à medida que em outras porções da bacia ocorreram aumento das duas classes (agricultura e pecuária). As maiores probabilidades de mudanças da classe pecuária ocorreram para as classes mata $(23,56 \%)$ e canade-açúcar (12,44\%).

\section{Validação da simulação do uso do solo em $t_{3}$ (2015)}

As figuras $7 \mathrm{a}-\mathrm{c}$ mostram os mapas de uso e ocupação do solo simulados para $t_{3}$ (2015) usando: (a) RNMLP, (b) o algoritmo SimWeight e (c) RL. Foi verificado que o uso do solo estimado, baseado em RNMLP, foi satisfatório, principalmente quando observadas as áreas em que a classe vegetação arbustiva foram substituídas pela classe agricultura (Figura 4c). Nas áreas próximas ao reservatório Tapacurá, também foi observado uma similaridade entre os mapas simulado (Figura 7a) através da RNMLP e o classificado (Figura 4c). Baseado nessa comparação pode-se destacar a mudança da classe vegetação arbustiva para a de cana-de-açúcar, além da expansão da classe pecuária. Com relação à classe área urbana, o mapa simulado apresentou uma expansão dessa classe, mais especificamente na porção central da bacia de maneira satisfatória. Em contrapartida, foi observado que o mapa simulado com RNMLP apresentou expansão da classe área urbana também nas porções leste e oeste da bacia, de maneira não satisfatória quando comparado com o mapa classificado (Figura 4c).

Quanto ao mapa simulado para $t_{3}$ (2015) usando o algoritmo SimWeight (Figura 7b), verificou-se que nas áreas com declividades mais baixas, o mapa simulado apresentou a mesma configuração do mapa classificado para $t_{2}$ (2007) (Figura 4b), no qual a área que deveria sofrer substituição da classe vegetação arbustiva para cana-de-açúcar não foi simulada pelo SimWeight. Notou-se ainda, que no mapa simulado com o SimWeight, (Figura 7b) a porção oeste da bacia apresentou alteração da classe vegetação arbustiva para agricultura, como verificado no mapa classificado (Figura 4c), em contrapartida, foram observadas de maneira insatisfatória a persistência da classe vegetação arbustiva, principalmente na porção noroeste da bacia. Esse resultado deveu-se, sobretudo à limitação do método de simulação com o SimWeight, no qual é permitida apenas uma transição.

Em relação ao mapa simulado para $t_{3}$ (2015) usando o método de RL (Figura 7c), observouse que próximo ao Reservatório Tapacurá foi constatado alteração da classe vegetação arbustiva para agricultura, bem como na porção noroeste e norte da bacia.

A classe área urbana não foi simulada satisfatoriamente com o método de RL, uma vez que não foi apresentado aumento dessa classe, sobretudo na porção central da bacia, como verificado no mapa classificado para 2015 (Figura 4c). A limitação da expansão das classes área urbana, cana-de-açúcar e pecuária obtidas com o método de RL, deveuse à restrição do método $\mathrm{RL}$ em simular a cobertura do solo apenas com uma transição na etapa de previsão do potencial de transição, que no caso foi construído apenas com a transição de vegetação arbustiva para agricultura.

A figura 8 apresenta a espacialização da validação realizada com o LCM da cobertura do solo simulado para $t_{3}$ (2015) usando: (a) RNMLP, (b) o algoritmo SimWeight e (c) RL. 

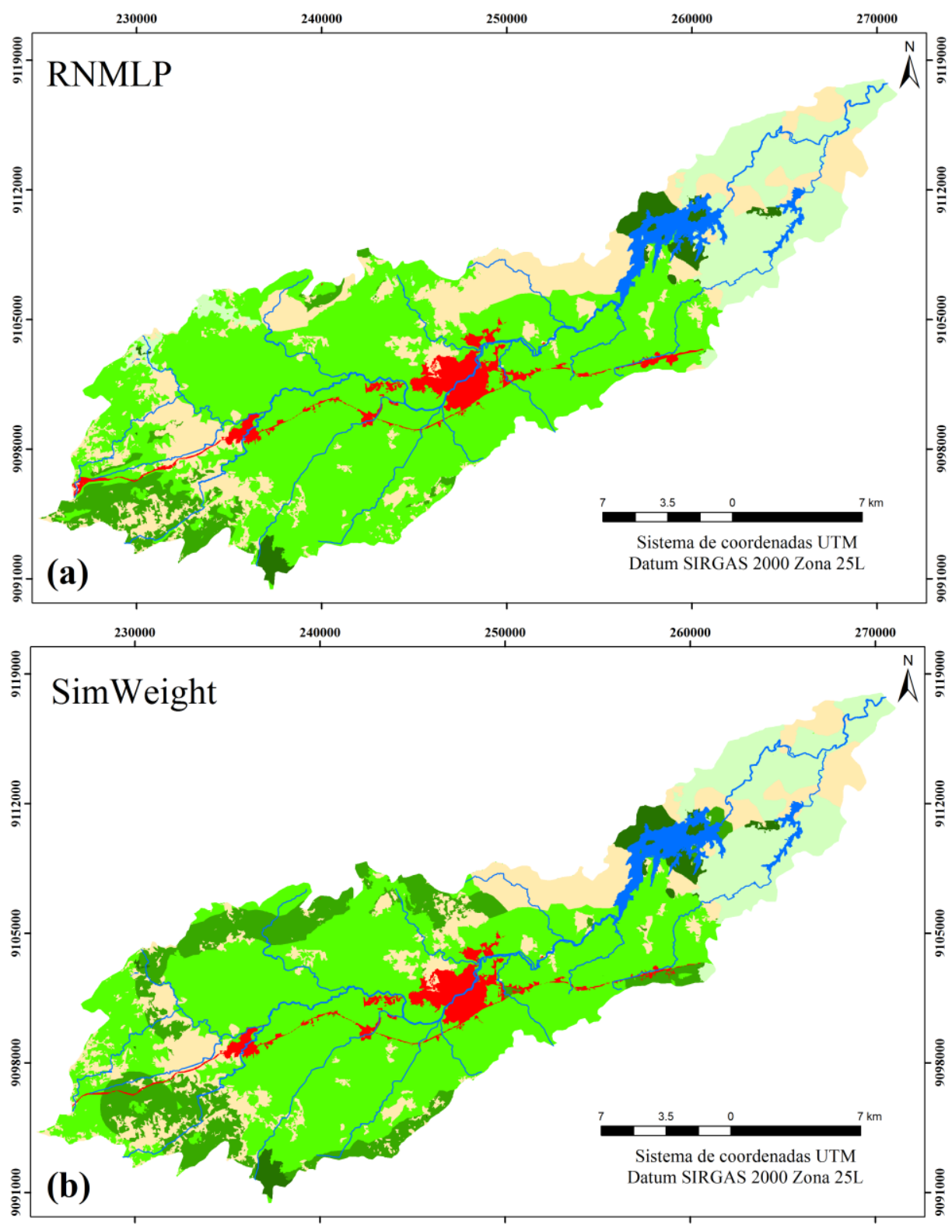

Uso e ocupação do solo simulado para t3 (2015)

3 Água $\longrightarrow$ Rios

03 Área urbana

Cana de açúcar

Mata

Pecuária

13 Agricultura

3 Vegetação arbustiva

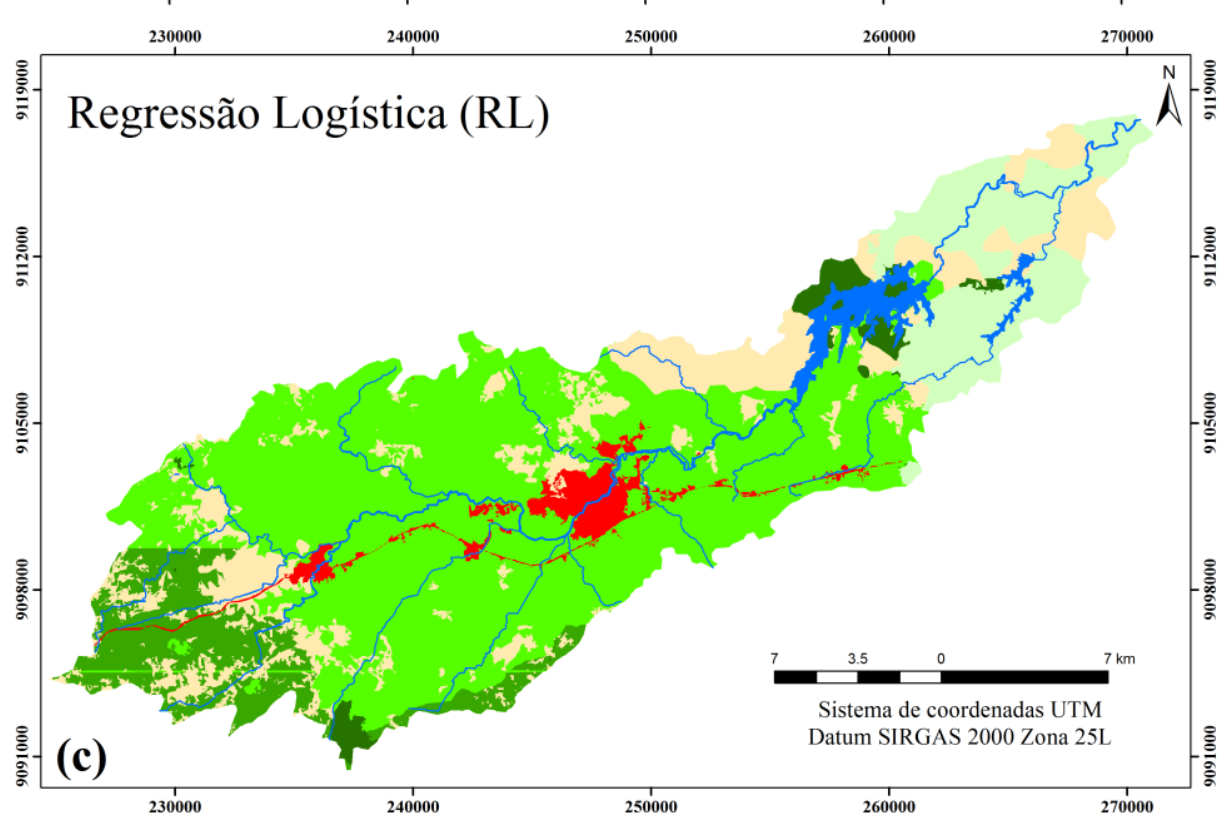

Figura 7 - Mapas de uso e ocupação do solo simulados para t 3 (2015) através: (a) RNMLP, (b) SimWeight e (c) RL. 

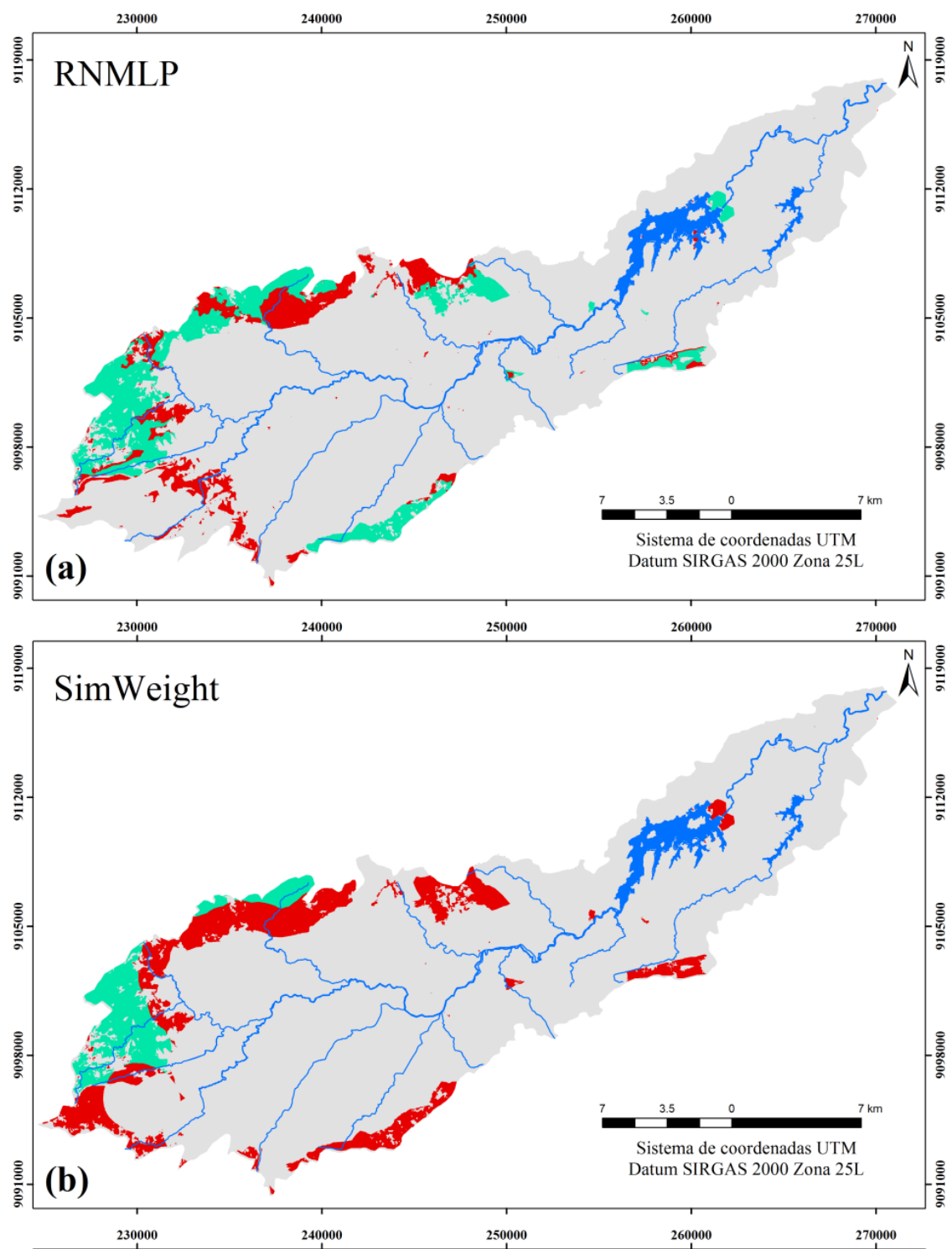

Validação com o LCM

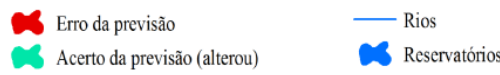

Acerto da previsão (não alterou)

3 Reservatório

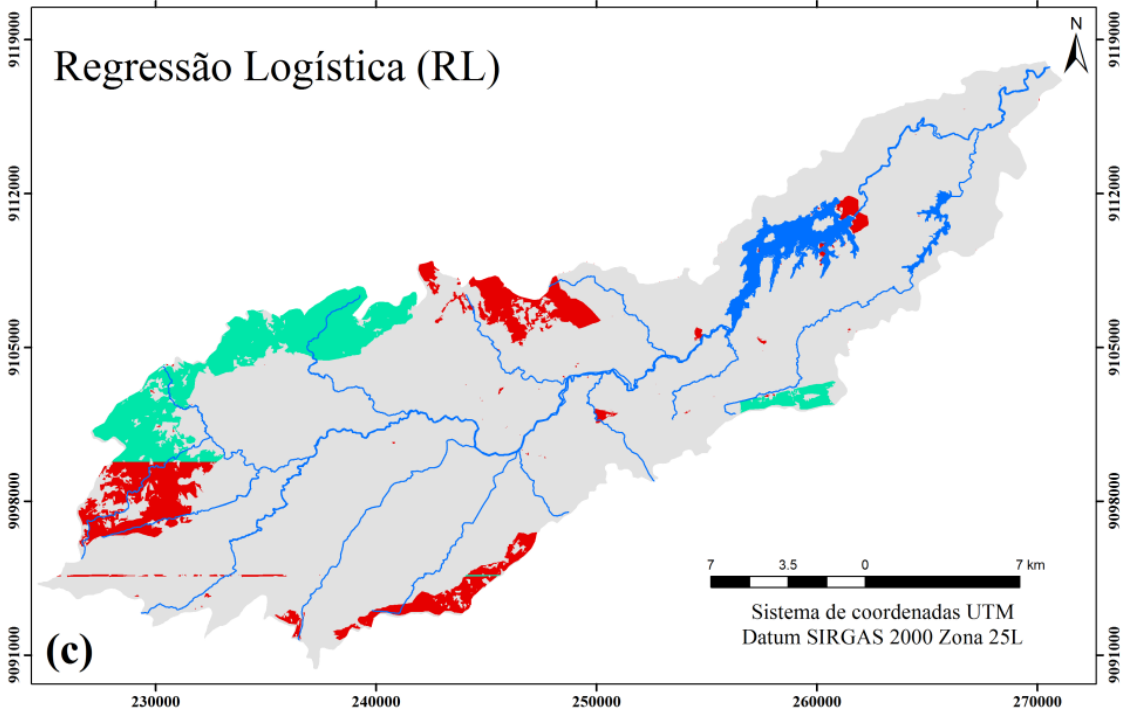

Figura 8 - Validação da cobertura do solo simulado para t ${ }_{3}$ (2015) (a) RNMLP; (b) SimWeight e (c) RL.

A tabela 4 mostra o resultado da validação com o LCM, com a quantificação (em km²) das áreas que apresentaram erro e acerto da previsão, para as três metodologias utilizadas de predição do uso e ocupação do solo.
Verificou-se que a simulação do uso e ocupação do solo usando a metodologia de RNMLP apresentou melhores resultados, com acerto da previsão de $442,80 \mathrm{~km}^{2}$, e o menor erro na previsão de $27,20 \mathrm{~km}^{2}$, quando comparado 
com os métodos SimWeight e RL. A simulação com o SimWeight apresentou acerto da previsão de $424,74 \mathrm{~km}^{2}$. Em contrapartida, o método SimWeight mostrou maior erro $\left(45,26 \mathrm{~km}^{2}\right)$.

Tabela 4 - Áreas de Erros e acertos da previsão após a validação com LCM.

\begin{tabular}{c|ccc}
\hline Validação com LCM & \multicolumn{3}{c}{ Métodos } \\
\cline { 2 - 4 } & RNMLP $\mathbf{( k m}^{\mathbf{2}}$ & SimWeight $\left(\mathbf{k m}^{\mathbf{2}}\right)$ & $\left.\mathbf{R L} \mathbf{( k m}^{\mathbf{2}}\right)$ \\
\hline Erro da previsão: cor vermelha & 27,20 & 45,26 & 29,34 \\
Acerto da previsão (alterou): cor verde & 40,63 & 20,57 & 32,48 \\
Acerto da previsão (não alterou): cor cinza & 402,17 & 404,17 & 408,18 \\
\hline
\end{tabular}

O método RL resultou um acerto da previsão de 440,66 $\mathrm{km}^{2}$. Esse método mostrou resultados de simulação de uso do solo semelhantes ao método de RNMLP, no entanto a porção oeste da bacia não mostrou resultados satisfatórios com o método RL, pois nessa porção foram encontrados maiores erros da previsão usando RL (Figura 8). Dessa maneira, a etapa de validação com LCM mostrou melhor desempenho na simulação da previsão para $t_{3}$ (2015) usando a metodologia baseada em RNMLP. Logo, a simulação para $t_{4}$ (2035) do uso e ocupação do solo para a bacia foi realizada baseada na metodologia de RNMLP, devido ao melhor desempenho demonstrado.

\section{Cenários de uso e ocupação do solo simulado para $t_{4}$ (2035)}

A figura 9 mostra o cenário 1 simulado para $\mathrm{t}_{4}$ (2035). Esse cenário se caracterizou pela continuidade das transições observadas na bacia durante 1989 e 2015. Em que as principais mudanças identificadas na bacia foram a substituição das áreas ocupadas pela classe vegetação arbustiva por áreas de cultivo (agricultura e cana-de-açúcar), área urbana e pecuária.

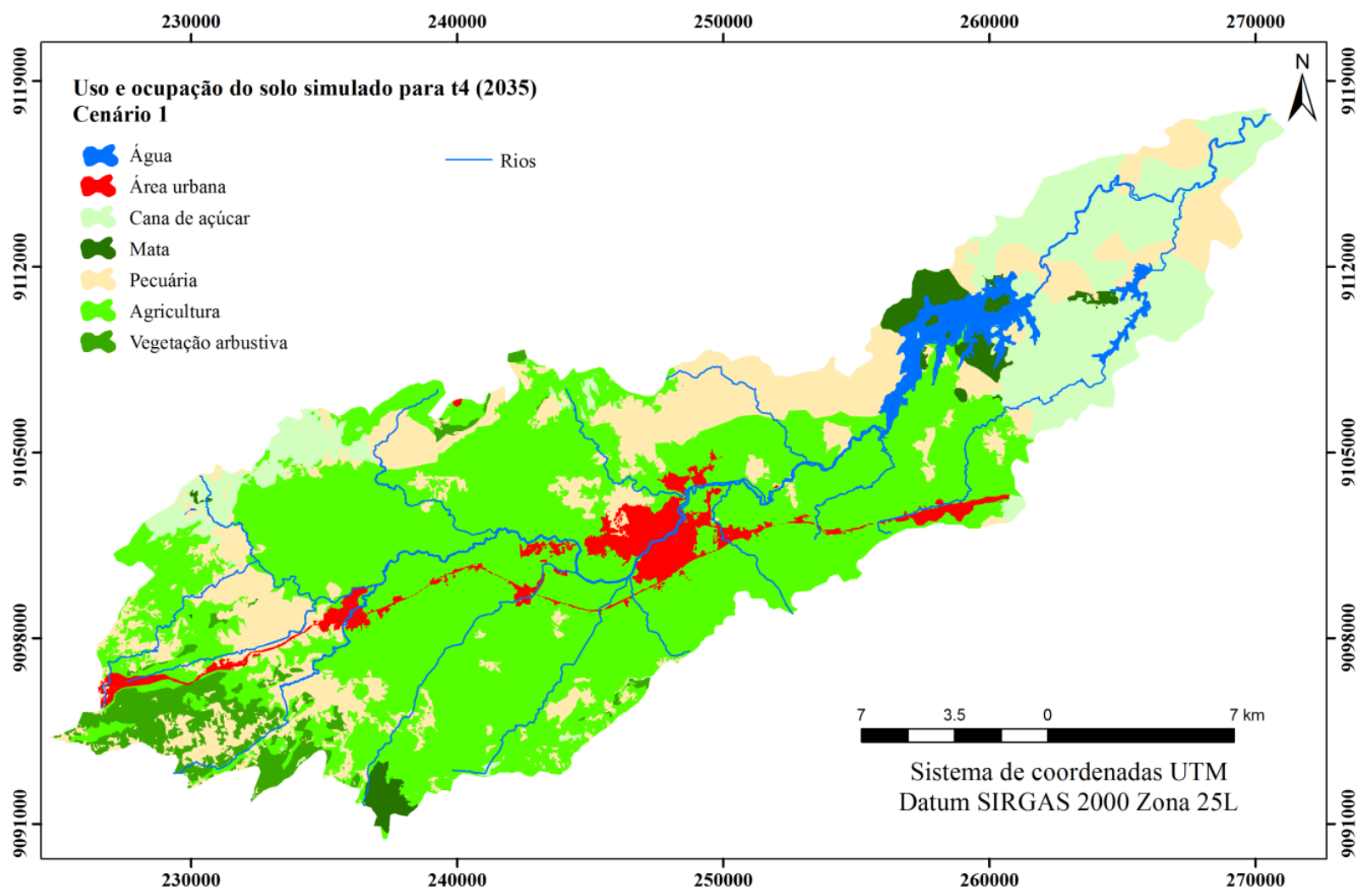

Figura 9 - Mapa de uso e ocupação do solo simulado para t 4 (2035): Cenário 1: Continuidade das transições.

Em 20 anos, para o cenário 1, a classe de cobertura com maior possibilidade para expansão é a cana-de-açúcar, com expansão de aproximadamente $10,49 \quad \mathrm{~km}^{2}$, quando comparado ao ano de 2015. De acordo com a predição realizada para $t_{4}$ (2035), o cenário de continuidade das transições mostrou significativas alterações para a porção oeste da bacia, uma vez que era a região com maior área ocupada por vegetação arbustiva em 2015. Para 
a classe área urbana, foi previsto um aumento de 3,56 km² com relação ao ano de 2015, observado principalmente nas porções central, leste e oeste da bacia, sendo consideradas as áreas mais vulneráveis à ocorrência de mudanças para a classe de área urbana. Para a classe pecuária, foi previsto aumento de 1,61\%, que corresponde a um crescimento de $7,58 \mathrm{~km}^{2}$, quando comparado ao ano de 2015, em detrimento da diminuição das áreas de vegetação arbustiva e agricultura de 2,05\% e 2,55\%, respectivamente, representando uma variação de $-35,55 \%$ e $-4,56 \%$, respectivamente. Com relação às classes água $\left(10,59 \mathrm{~km}^{2}\right)$ e mata $\left(9,85 \mathrm{~km}^{2}\right)$, não foi previsto variação, comparando-se com o ano de 2015.

A figura 10 mostra o segundo cenário simulado para $t_{4}$ (2035). Esse cenário 2 também foi simulado baseado em uma RNMLP e na continuidade das transições observadas na bacia para os anos de 1989, 2007 e 2015, mas com ressalva para intensificação da classe pecuária e expansão da classe de área urbana. Para o cenário 2, foi previsto diminuição de $11,02 \mathrm{~km}^{2}$ (2,34\%) da classe de vegetação arbustiva, com relação ao ano de 2015, além da redução de 1,94\% da classe de agricultura. A classe pecuária mostrou maior variação de área ocupada com relação a 2015 (cerca de 15\%), seguida da área urbana (13,97\%) e cana-de-açúcar (7,92\%). O aumento da classe pecuária foi prevista para as porções sudoeste e norte, e da classe área urbana nas regiões central, leste e oeste, e a de cana-de-açúcar na porção noroeste da bacia.

Comparando com o cenário 1, notou-se que mesmo com a intensificação da classe área urbana para o cenário 2, esta classe mostrou área ocupada um pouco menor do que o cenário 1 , com diferença de aproximadamente $1 \mathrm{~km}^{2}$. Esse resultado demonstrou que a área urbana na bacia não apresenta significativa probabilidade para expansão em $t_{4}$ (2035).

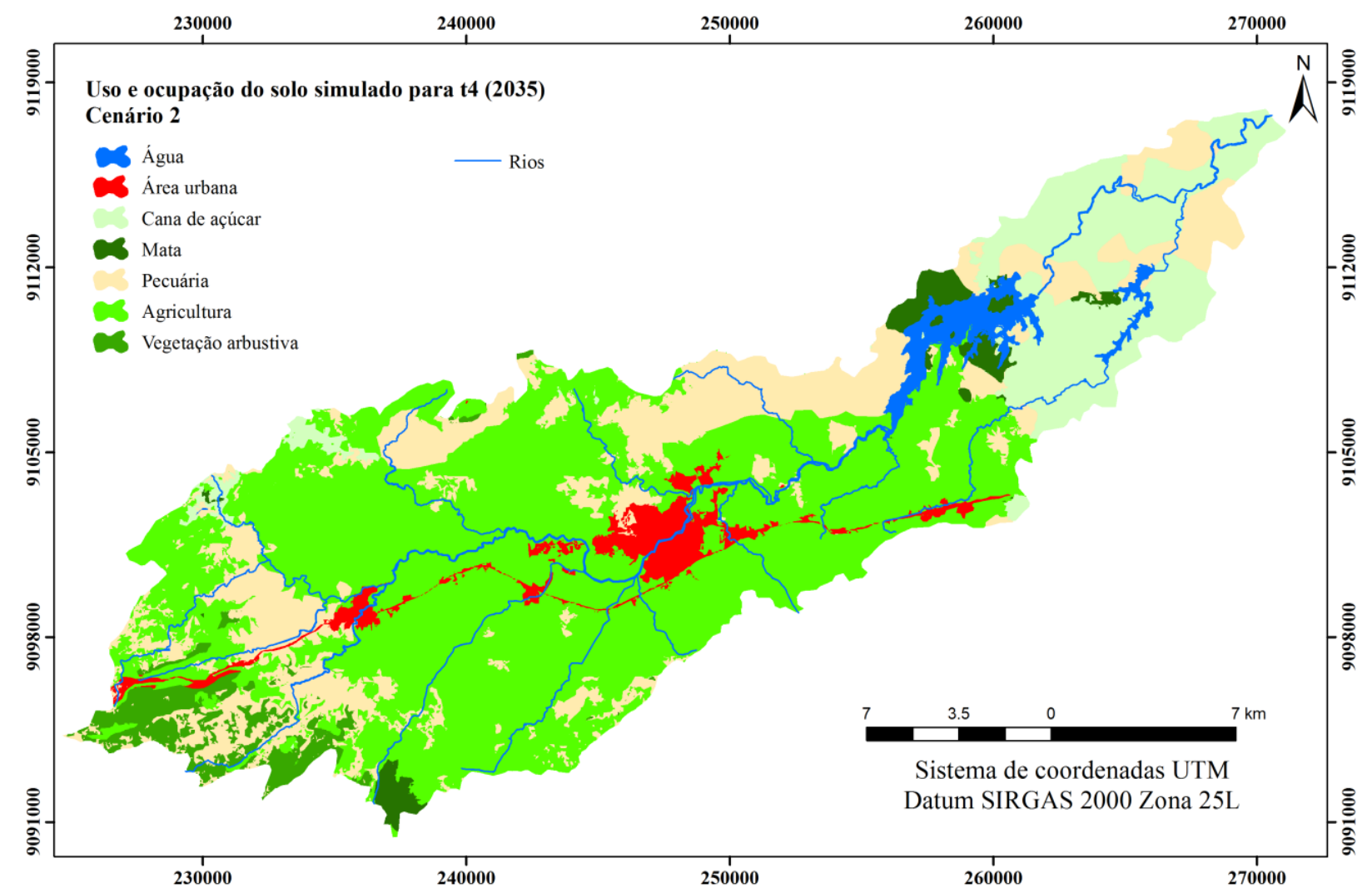

Figura 10 - Mapa de uso e ocupação do solo simulado para t4 (2035): Cenário 2: Continuidade e intensificação da atividade pecuária e expansão de áreas urbanas.

Na tabela 5 são apresentadas as áreas totais de ocupação de cada cobertura do uso do solo na bacia do Rio Tapacurá para 2015 e para os outros dois cenários simulados. Observou-se que para as classes água e mata não foram previstas modificações, enquanto que as classes de área urbana, cana-de-açúcar, pecuária, agricultura e vegetação arbustiva mostraram previsão para mudanças no uso do solo, para os dois cenários simulados. 
Tabela 5 - Área de abrangência das classes de uso e ocupação do solo em 2015 e para os cenários simulados previsto t 4 (2035) na bacia do Rio Tapacurá

\begin{tabular}{|c|c|c|c|c|c|c|}
\hline \multirow{2}{*}{$\begin{array}{c}\text { Uso e ocupação } \\
\text { do solo }\end{array}$} & \multirow{2}{*}{$\begin{array}{l}\text { Área total em } \\
2015\left(\mathrm{~km}^{2}\right)\end{array}$} & \multirow{2}{*}{$\%$} & \multicolumn{2}{|c|}{ Cenário 1} & \multicolumn{2}{|c|}{ Cenário 2} \\
\hline & & & Área $\left(\mathbf{k m}^{2}\right)$ & $\%$ & Área $\left(\mathbf{k m}^{2}\right)$ & $\%$ \\
\hline Água & 10,59 & 2,25 & 10,59 & 2,25 & 10,59 & 2,25 \\
\hline Área urbana & 15,89 & 3,38 & 19,45 & 4,14 & 18,11 & 3,85 \\
\hline Cana-de-açúcar & 55,90 & 11,89 & 66,39 & 14,13 & 60,33 & 12,84 \\
\hline Mata & 9,85 & 2,10 & 9,85 & 2,10 & 9,85 & 2,10 \\
\hline Pecuária & 87,50 & 18,62 & 95,08 & 20,23 & 100,98 & 21,49 \\
\hline Agricultura & 263,21 & 56,00 & 251,20 & 53,45 & 254,10 & 54,06 \\
\hline Vegetação arbustiva & 27,06 & 5,76 & 17,44 & 3,71 & 16,04 & 3,41 \\
\hline Total & 470 & 100 & 470 & 100 & 470 & 100 \\
\hline
\end{tabular}

\section{CONCLUSÕES}

O estudo identificou considerável modificação quanto ao uso e ocupação do solo na bacia do Rio Tapacurá, para os anos de 1989, 2007 e 2015, sendo a maior parte das áreas ocupadas por vegetação arbustiva, substituídas por atividades de agricultura, canade-açúcar e pecuária. Comparando-se os anos de 1989 e 2015, foi identificado também o aumento da área urbana de aproximadamente 2,5\% da área da bacia. Além do aumento do sistema de abastecimento de água da região, com a construção do reservatório Várzea do Una.

Foi verificado que o uso do solo estimado, baseado em RNMLP, foi satisfatório, principalmente quando observadas as áreas em que a classe vegetação arbustiva foram substituídas pela classe agricultura. A simulação de cenários de uso e ocupação do solo para 2035 na bacia do Rio Tapacurá apontou para cenários de intensificação das transições observadas para os anos de 1989, 2007 e 2015, no qual foi previsto que os principais usos do solo serão para atividades agropecuárias, com intensificação das classes de agricultura, pecuária, área urbana e canade-açúcar, no entanto, para os dois cenários simulados uma das classes mais representativas é a agricultura.

\section{REFERÊNCIAS}

AMORIM, J.A.F. Análise e modelação da mudança da ocupação e uso do solo: Caso de estudo da bacia hidrográfica do rio Vez. Dissertação de Mestrado em Gestão Ambiental e Ordenamento do território, Instituto Politécnico de Viana do Castelo- Escola Superior Agrária, Ponte de Lima, 129p., 2015.

BRAGA, R.A.P. Gestão ambiental da Bacia do Rio Tapacurá: plano de ação. Recife: Ed. Universitária da Universidade Federal de Pernambuco, 101p., 2001.

CASTRO, K.B. Avaliação do modelo SWAT na simulação da vazão em bacia agrícola do Cerrado intensamente monitorada. Dissertação de Mestrado em Geociências, Universidade de Brasília, Brasília, 122p., 2013.

CHENG, S.; DING, N. Land Change Modeler Application: Summer Internship with Clark Labs. Bélgica: Editora International Development, Community and Environment (IDCE). p. 57, 2016.

DEUS, L.A.B. Espaço e tempo como subsídios à construção de cenários de uso e cobertura da terra para o planejamento ambiental na Amazônia: o caso da bacia do Rio Acre. Tese de Doutorado em Planejamento Energético, Universidade Federal do Rio de Janeiro, Rio de Janeiro, 400p., 2013.

DIAS, L.T.; WALDE, D.H.G. Modelagem da dinâmica espacial do uso e ocupação do solo na bacia hidrográfica do Lago Paranoá-DF. Revista Brasileira de Cartografia, v. 65, n. 1, p. 77-94, 2013.

DUARTE, C.C Análise dos impactos das mudanças climáticas no escoamento superficial da bacia hidrográfica do Rio Tapacurá- PE, a partir da utilização de um modelo de balanço hídrico mensal semi-distribuído. Recife, 125p., 2009 .Dissertação (Mestrado em Geografia), Universidade Federal de Pernambuco.

DUTRA, M.T.D. Uso dos recursos hídricos e florestais e sua relação com as áreas de preservação permanente na bacia do Riacho Gameleira, afluente do Tapacurá- PE. Recife, 107p., 2005. Dissertação (Mestrado em Engenharia Civil), Universidade Federal de Pernambuco.

EASTMAN J. R. Guide to GIS and Image Processing. Worcester, MA: Editora: Clark Labs da Clark University, 2003.

EASTMAN, J.R. IDRISI Selva: Guide to GIS and Image Processing. Worcester, MA: Editora: Clark Labs da Clark University, p. 327, 2011.

EMBRAPA - Empresa Brasileira de Agropecuária. Sistema Brasileiro de Classificação dos Solos. Rio de Janeiro: Editora EMBRAPA, 3ª edição, 2013.

FOLEY, J.A.; DEFRIES, R.; ASNER, G.P.; BARFORD, C.; BONAN, G.; CARPENTER, S.R.; CHAPIN, F.S.; COE, M.T.; DAILY, G.C.; GIBBS, H.K.; HELKOWSKI, J.H.; HOLLOWAY, T.; HOWARD, E.A.; KUCHARIK, C.J.; MONFREDA, C.; PATZ, J.A.; PRENTICE, I.C.; RAMANKUTTY, N.; SNYDER, P.K. Global consequences of land use. Science, v. 309, n. 5734, p. 570-574, 2005.

FUNDARPE - Fundação do Patrimônio Histórico e Artístico de Pernambuco. Mapa cultural. Disponível em: http://www.mapacultural.pe.gov.br/inicial/shapefile.htm. Acesso em: 08/08/2016. 
HAMDY, O.; ZHAO, S.; SALHEEN, M.A.; EID, Y.Y. Analyses the Driving Forces for Urban Growth by Using IDRISI Selva Models Abouelreesh - Aswan as a Case Study. International Journal of Engineering and Technology, v. 9, n. 3, p. 226-232, 2017.

KHAWALDAH, H.A. A Prediction of Future Land Use/Land Cover in Amman Area Using GIS Based Markov Model and Remote Sensing. Journal of Geographic Information System, v. 8, p. 412-427, 2016.

LIEBERTRAU, A.M. Measures of association. Newbury Park, CA: Sage Publications. Quantitative, 1983.

LUIZ, C.H.P. Modelagem da cobertura da terra e análise da influência do reflorestamento na transformação da paisagem: Bacia do Rio Piracicaba e Região Metropolitana do Vale do Aço. Dissertação de Mestrado em Análise e Modelagem de Sistemas Ambientais, Universidade Federal de Minas Gerais, Belo Horizonte, 141p., 2014.

MACEDO, R.C.; ALMEIDA, C.M.; SANTOS, J.R.; B.F.T. RUDORFF. Modelagem dinâmica espacial das alterações de cobertura e uso da terra relacionada à expansão canavieira. Boletim de Ciências Geodésicas, v. 19, n. 2, p. 313-337, 2013.

MAS, J.F.; KOLB, M.; PAEGELOW, M.; OLMEDO, M.C.; HOUET, T. Modelling Land use/cover changes : a comparison of conceptual approaches and softwares. Environmental Modelling and Software, v. 51, p. 94-111, 2014.

MISHRA, V.N.; RAI, P.K.; MOHAN, K. Prediction of land use changes based on land change modeler (LCM) using remote sensing: a case study of Muzaffarpur (Bihar), Índia. Journal of the Geographical Institute Jovan Cvijic, v. 64, p. 111127, 2014.

OLIVEIRA, L.M.M. Estimativa da evapotranspiração real por sensoriamento remoto na bacia do Rio Tapacurá PE. Tese de Doutorado em Engenharia Civil, Universidade Federal de Pernambuco, Recife, 156 f., 2012.

PIROLI, E.L. Geoprocessamento aplicado ao estudo da evolução do uso da terra e seus impactos sobre a infiltração de água em microbacias hidrográficas. Anais... XLIII Congresso Brasileiro de Engenharia Agrícola, Campo Grande-MS, 2014.

SAMPAIO, D.M. Modelagem da cobertura do solo urbano no Vetor Norte da RMBH e projeções de cenários futuros considerando as novas infraestruturas viárias previstas. Dissertação (Mestrado em Análise e Modelagem de Sistemas Ambientais)- Universidade Federal de Minas Gerais, Belo Horizonte, 103 f., 2014.
SANGERMANO, F.; TOLEDANO, J.; EASTMAN, J.R. Land cover change in the Bolivian Amazon and its implications for REDD+ and endemic biodiversity. Landscape Ecology, v. 27, p. 571-584, 2012.

SANTOS, J.Y.G. Implicações das mudanças do clima e uso do solo nos processos hidrossedimentológicos da bacia do rio Tapacurá. Recife, 210p., 2015. Tese (Doutorado em Engenharia Civil), Universidade Federal de Pernambuco.

SILVA, R.M. Análise da perda de solos na Bacia do Rio Tapacurá mediante previsão climática e modelos de erosão. Tese (Doutorado em Engenharia Civil)- Universidade Federal de Pernambuco, Recife - PE, 133f. 2010.

SILVA, R.M.; MONTENEGRO, S.M.G.; SANTOS, C.A.G. Integration of GIS and remote sensing for estimation of soil loss and prioritization of critical sub-catchments: a case study of Tapacurá catchment. Natural Hazards, v. 63, n. 3, p. 576592, 2012.

SOARES FILHO, B.S.; RODRIGUES, H.; FOLLADOR, M. A hybrid analytical-heuristic method for calibrating land-use change models. Environmental Modelling Software, v. 43, p. 80-87, 2013.

VALERIANO, M.M. Modelo digital de variáveis morfométricas com dados SRTM para o território nacional: o Projeto TOPODATA. In: Simpósio Brasileiro de Sensoriamento Remoto XII, Goiânia. 2005. Anais...Goiânia: INPE, p. 1-8.

VALERIANO, M.M.; ROSSETTI, D.F.; ALBUQUERQUE, P.C.G. Topodata: desenvolvimento da primeira versão do banco de dados geomorfométricos locais em cobertura nacional. In: Simpósio Brasileiro de Sensoriamento Remoto XIV, Natal. 2009. Anais...Natal: INPE, p. 1-8.

XIONG, X.; GRUNWALD, S.; MYERS, D.B.; ROSS, C.W.; HARRIS, W.G.; COMERFORD, N.B. Interaction effects of climate and land use/land cover change on soil organic carbon sequestration. Science of The Total Environment, v. 15, p. 974-82, 2014.

ZANATA, J.M. Mudanças no uso e cobertura da terra na bacia hidrográfica do Ribeirão Bonito, municípios de Avaré e Itatinga- SP. Presidente Prudente, 123p., 2014. Dissertação de Mestrado em Geografia, Universidade Estadual Paulista. 